\title{
Local and systemic signaling of iron status and its interactions with homeostasis of other essential elements
}

\author{
Sheena R. Gayomba, Zhiyang Zhai, Ha-il Jung and Olena K. Vatamaniuk* \\ Soil and Crop Sciences Section, School of Integrative Plant Sciences, Cornell University, Ithaca, NY, USA
}

Iron $(\mathrm{Fe})$ is essential for plant growth and development. However, alkaline soils, which occupy approximately $30 \%$ of the world's arable lands, are considered Fe-limiting for plant growth because insoluble Fe (III) chelates prevail under these conditions. In contrast, high bioavailability of $\mathrm{Fe}$ in acidic soils can be toxic to plants due to the ability of Fe ions to promote oxidative stress. Therefore, plants have evolved sophisticated

OPEN ACCESS

Edited by: Jon Pittman,

University of Manchester, UK

Reviewed by: Wolfgang Schmidt, Academia Sinica, Taiwan Takanori Kobayashi, Ishikawa Prefectural University, Japan

${ }^{*}$ Correspondence: Olena K. Vatamaniuk, Soil and Crop Sciences Section, School of Integrative Plant Sciences, Cornell University, 360 Tower Road, 608 Bradfield Hall, Ithaca, NY 14853,

USA

okv2@cornell.edu

Specialty section:

This article was submitted to

Plant Traffic and Transport, a section of the journal

Frontiers in Plant Science

Received: 06 July 2015

Accepted: 27 August 2015

Published: 14 September 2015

Citation:

Gayomba SR, Zhai Z, Jung H and Vatamaniuk OK (2015) Local and systemic signaling of iron status and its interactions with homeostasis

of other essential elements.

Front. Plant Sci. 6:716.

doi: 10.3389/fp/s.2015.00716 mechanisms to sense and respond to the fluctuation of Fe availability in the immediate environment and to the needs of developing shoot tissues to preclude deficiency while avoiding toxicity. In this review, we focus on recent advances in our understanding of local and systemic signaling of Fe status with emphasis on the contribution of $\mathrm{Fe}$, its interaction with other metals and metal ligands in triggering molecular responses that regulate Fe uptake and partitioning in the plant body.

Keywords: Arabidopsis thaliana, iron homeostasis, iron transporters, iron signaling, iron ligands, oligopeptide transporters

\section{Introduction}

Iron $(\mathrm{Fe})$ is essential for growth and development of all organisms, but can be toxic to cells in excess. The essential, yet toxic nature of $\mathrm{Fe}$ results from its ability to change the oxidation state $\left(\mathrm{Fe}^{3+} \leftrightarrow \mathrm{Fe}^{2+}\right.$; Marschner, 1995). Therefore, Fe participates in electron transfer reactions and is central to the function of heme- and $\mathrm{Fe}-\mathrm{S}$ cluster-requiring enzymes participating in biological processes that include respiration, photosynthesis, sulfur assimilation, and nitrogen fixation (Marschner, 1995). However, non-coordinated $\mathrm{Fe}$ ions catalyze the formation of reactive oxygen species via Fenton reaction and might mismetallate essential cellular molecules, further exacerbating cellular damage (Valko et al., 2005). Therefore, internal Fe ions not associated with metalloenzymes are distributed among low molecular weight (LMW) ligands and constitute the labile (alias bioavailable) $\mathrm{Fe}$ pool. In this form, $\mathrm{Fe}$ is available for equilibration with metalloregulators and metalloenzymes via ligand exchange reactions to perform essential cellular functions (Hider and Kong, 2013). The concentration of the cytosolic labile Fe pool is defined in accordance with $\mathrm{Fe}$ needs of the plant through the ability of plants to sense changes in Fe bioavailability in the rhizosphere, in the cytosol and in the developing shoot, and integrate local and long-distance signaling events into a concerted action of Fe transporters and their regulators. Evidence of local and systemic signaling networks and crosstalk between them have been accumulating for more than a decade and are based on characteristic root responses to Fe deficiency such as the increase of the root surface-associated proton extrusion activity and the transcriptional responses of the $\mathrm{Fe}$ uptake system. As exemplified by studies in 
Arabidopsis thaiana, IRT1 (Iron-Regulated Transporter 1, encoding a high-affinity $\mathrm{Fe}$ (II) transporter) and FRO2 (Ferric Reduction Oxidase 2, encoding a ferric chelate reductase) are transcriptionally regulated in response to local and long-distance signals of Fe availability, and these types of proteins constitute the major entry point of $\mathrm{Fe}$ into root epidermal cells in non-gramenaceous plants (reviewed in, Hindt and Guerinot, 2012; Kobayashi and Nishizawa, 2012).

Regulation of Fe uptake by locally originated signals have been observed in potato (Solanum tuberosum) by Bienfait et al. (1985). Roots of potato growing on low Fe nutrient solution exhibit increased proton extrusion and ferric reductase activity with, as well as without the sprout, pointing to the existence of a local, shoot-independent Fe deficiency signaling network in the root. Local Fe supply also triggers lateral root elongation in Arabidopsis thaliana (Giehl et al., 2012). On the other hand, ferric chelate reductase activity in roots of pea (Pisum sativum) fluctuates during the life cycle even when plants are grown under continues Fe supply, and is lowered when phloem transport to roots is interrupted (Grusak, 1995). This result suggested the existence of a shoot-borne signal that communicates Fe demands to the root. The latter hypothesis was further substantiated by results from experiments using the split-root system in Plantago lanceolata and $A$. thaliana showing that ferric chelate reductase activity increases in the half of the root grown with Fe, suggesting that shoots transmit an Fe-deficiency signal from the Fe-deficient to Fe-sufficient half of the root (Romera et al., 1992; Schmidt et al., 1996; Vert et al., 2003). Further, local and long-distance signals do not act independently from one another. Crosstalk between local and long-distance control of Fe deficiency response was shown by finding that while lateral root elongation in response to localized Fe supply is severely repressed in the irt1 mutant of A. thaliana lacking functional $\mathrm{Fe}$ (II) transporter, the requirements for IRT1 is circumvented by the application of Fe to the shoot (Giehl et al., 2012).

These experiments raised many questions regarding the sites of signal(s) generation, the nature of local and shootborne signals, as well as sensors/receptors, which perceive and transduce information about local and long-distance Fe availability. Hormones, Fe-binding ligands, and recirculating $\mathrm{Fe}$ ions themselves have been proposed to act as local and long-range signals promoting Fe-deficiency responses in the root. Notably, fluctuation of cellular Fe concentration alters ratios of other transition elements and thus, has a profound effect on the metal composition of the cell (the metallome). Therefore, since many transition metals are close in their coordination geometry and ligand preferences (Haas and Franz, 2009), mismetallation of Fe-requiring apoenzymes and metalloregulators may occur under $\mathrm{Fe}$ deficient conditions, affecting Fe signaling and downstream transcriptional and posttranscriptional events. This review focuses mainly on the role of labile $\mathrm{Fe}, \mathrm{Fe}$ ligands, and crosstalk among essential elements in local and systemic Fe status signaling. Involvement of other factors in Fe status signaling is reviewed in (Hindt and Guerinot, 2012; Kobayashi and Nishizawa, 2012, 2014).

\section{Overview of Fe uptake, Root-to-Shoot Partitioning, and Speciation in Plant Tissues}

Our understanding of signaling events regulating Fe status in the cell is based on tracking several characteristic responses of Fe transport systems summarized below. To acquire Fe from the rhizosphere, non-graminaceous, and graminaceous plants use the reduction strategy (Strategy I) and the chelation strategy (Strategy II), respectively (Marschner and Romheld, 1994). For an overview of the chelation strategy, we would like to refer the reader to (Walker and Connolly, 2008; Hindt and Guerinot, 2012). This review will focus on the components of the $\mathrm{Fe}$ transport machinery in plants utilizing the reduction strategy (Figure 1). In brief, this strategy includes the acidification of the rhizosphere by root plasma membrane $\mathrm{H}^{+}$- ATPases, which increase the solubility of Fe(III) (Santi and Schmidt, 2009) and the reduction of $\mathrm{Fe}$ (III) chelates to soluble $\mathrm{Fe}$ (II) by the root plasma membrane ferric chelate reductase, FRO2 in A. thaliana and FRO1 in Pisum sativum (Robinson et al., 1999; Waters et al., 2002). The solubilized Fe(II) enters the apoplastic space where it constitutes up to $75 \%$ of the total $\mathrm{Fe}$ of the root (Bienfait et al., 1985). Although $\mathrm{Fe}$ can be remobilized from the apoplast into the symplast in any cell type of the root, the expression pattern of the key Fe transporter in A. thaliana, IRT1, suggests that the bulk of Fe(II) uptake into the symplast occurs in the root epidermal cells (Eide et al., 1996; Vert et al., 2002). The FRO2/IRT1-like system constitutes the major pathway for Fe entry into root epidermal cells of non-graminaceous plants. Given the essential and toxic nature of $\mathrm{Fe}$, expression of genes encoding root ferric chelate reductases and IRT1 is tightly regulated by Fe status and thus, has been used in studies of local and long-distance Fe status signaling (Hindt and Guerinot, 2012; Kobayashi and Nishizawa, 2012). A second "auxiliary" Fe uptake strategy involves the exudation of phenolic and flavin compounds into the rhizosphere during $\mathrm{Fe}$ deficiency to facilitate utilization of apoplastic $\mathrm{Fe}$ reserves (Bienfait et al., 1985; Jin et al., 2007; Lan et al., 2011; Rodríguez-Celma et al., 2011; Rodríguez-Celma and Schmidt, 2013; Schmid et al., 2014). Recent studies in grasses have shown that the protocatechuic acid effluxer Phenolics Efflux Zero 1 (PEZ1), is required for the mobilization of $\mathrm{Fe}$ in the stele of rice, and transgenic rice plants overexpressing PEZ1 grow better on soils with high $\mathrm{pH}$ and poor $\mathrm{Fe}$ availability (Ishimaru et al., 2011). PEZ1 counterpart has not been yet identified in non-graminaceous plants. However, recent studies in A. thaliana indicated that an ATP-binding cassette transporter ABCG37 (alias PDR9) is involved in secretion of phenolic compounds from roots into the medium in response to $\mathrm{Fe}$ deficiency (Rodríguez-Celma et al., 2013; Fourcroy et al., 2014).

After entering root epidermal cells, Fe moves symplastically via plasmodesmata toward the vasculature and is effluxed from xylem parenchyma cells into the xylem vessels where it is chelated by citrate to form a tri-Fe(III) tri-citrate complex to undergo long-distance transport to the shoot (Larbi et al., 2010; RellanAlvarez et al., 2010). The key identified players contributing to 


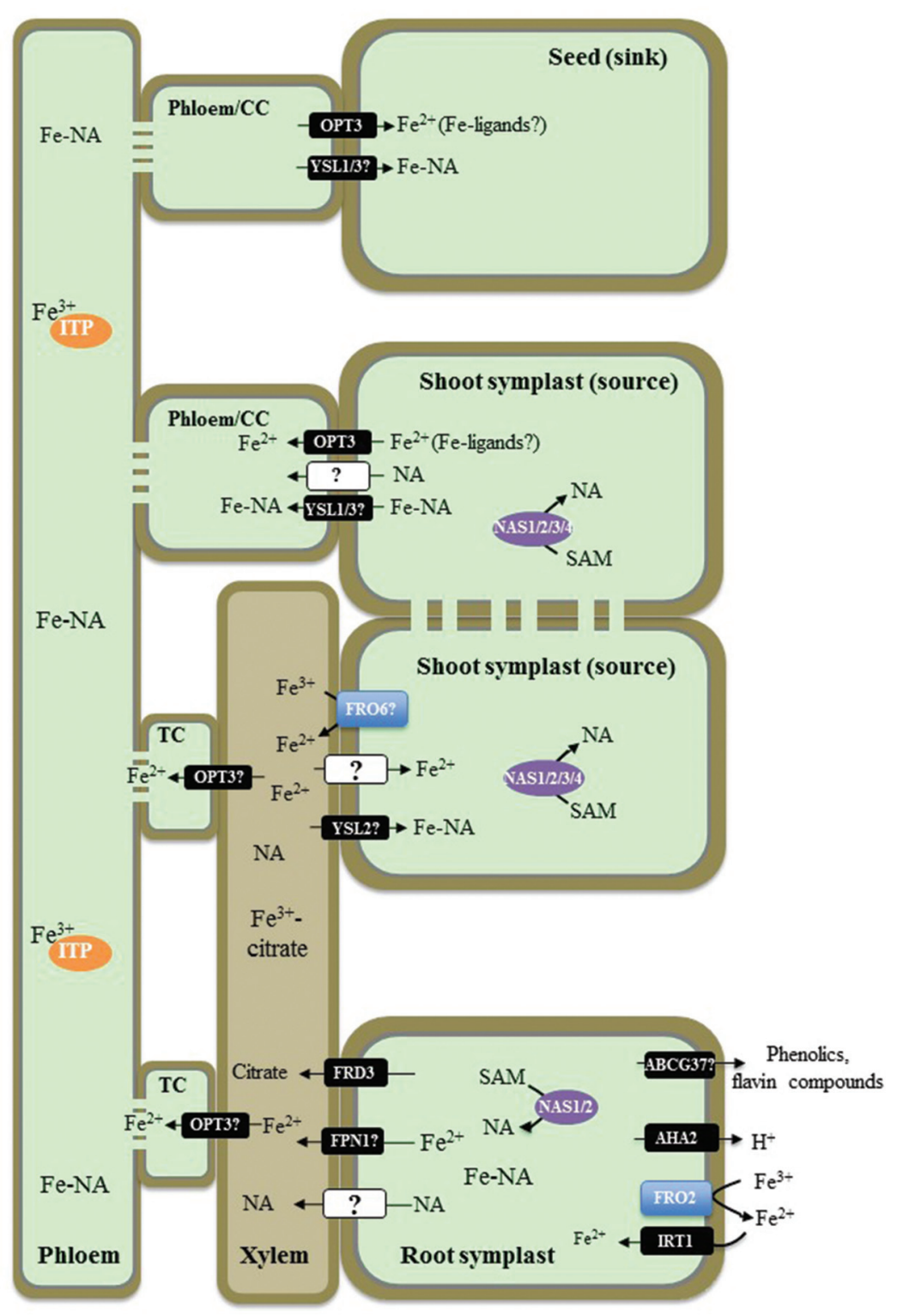

FIGURE 1 | Overview of iron ( Fe) transport in non-graminaceous plants based on studies in Arabidopsis thaliana. A proton pump, AHA2, contributes to the acidification of rhizosphere to facilitate solubilization of Fe(III) under Fe-limited conditions. Ferric-chelate reductase $\mathrm{FRO} 2$ reduces $\mathrm{Fe}$ (III) to $\mathrm{Fe}(\mathrm{II})$ at the root surface and $\mathrm{Fe}^{2+}$ is then transported into root epidermal cells by IRT1. Phenolic and flavin compounds are also exuded into the rhizosphere to facilitate Fe(III) solubilization by ABCG37/PDR9. Fe-NA chelates prevail in the cytosol, where nicotianamine (NA) in roots is produced by NASes. Fe-NA then moves radially via plasmodesmata toward the vasculature. FPN1 is implicated in loading Fe into the xylem vessels, while FRD3 provides citrate. In the xylem, Fe forms a (tri)Fe ${ }^{3+}$-(tri)citrate complex, which moves toward the shoot via the transpiration stream. In shoots Fe(III) is reduced likely by the action of the FRO family members. YSL2 is proposed to transport Fe-NA to photosynthetic cells (mesophyll cells). Whether the ionic form of Fe is reabsorbed from the xylem vessels into xylem parenchyma cells in the shoot, is not known. In the shoot symplast, Fe predominantly exists as Fe(II)-NA complex. Fe is then loaded into the phloem for subsequent partitioning to sink tissues such as young leaves, seeds as well as is recirculated to the root. OPT3 and YSL1 and YSL3 are implicated in Fe ${ }^{2+}$ and Fe-NA loading into the phloem, respectively. While Fe-NA is a predominant form of Fe in the phloem sap, Fe transporting protein (ITP), metallothionein-like protein type 2B, and a low-molecular weight protein with the similarity to a phloem-specific protein from $M$. truncatula, have been identified associated with Fe in the phloem sap of $R$. communis and $L$. texensis. CC, companion cells; TC, phloem companion cells that de-differentiated into transfer cells.

this process in A. thaliana are the Multidrug and Toxin Efflux family (MATE) member, FRD3, and one of two members of the Iron Regulated1/Ferroportin 1 family, IREG1/FPN1 (Green and Rogers, 2004; Durrett et al., 2007; Morrissey et al., 2009). FRD3 is located in the root pericycle (Rogers and Guerinot,
2002; Green and Rogers, 2004), transports citrate from xylem parenchyma cells into xylem vessels (Durrett et al., 2007) and acts in concert with IREG1/FPN1, which is proposed to mediate $\mathrm{Fe}$ efflux into xylem vessels (Morrissey et al., 2009). Citrate release into the apoplast via FRD3 plays an important role in partitioning 
Fe between the apoplast and symplast of cells surrounding xylem vessels in roots and leaf mesophyll cells (Roschzttardtz et al., 2011). The lack of proper long distance Fe transport in xylem vessels results in shoot chlorosis and deregulated $\mathrm{Fe}$ signaling in the $f r d 3$ mutant (discussed below). A mutation in IREG1/FPN1, however, does not prevent $\mathrm{Fe}$ accumulation in the root vasculature suggesting that another $\mathrm{Fe}$ transporter(s) operates redundantly with IREG1/FPN1 (Morrissey et al., 2009). Similar to $f r d 3$ mutants, A. thaliana fpn 1 mutant plants develop shoot chlorosis when grown in Fe-deficient media. However, the function of IRT1 and FRO2 in the fpn1 mutant is not affected, indicating that Fe signaling is not altered with the loss of IREG1/FPN1 (Morrissey et al., 2009).

Next steps of Fe transport within the plant include the reabsorption of Fe from the apoplast of xylem vessels in the shoot for distribution to leaf parenchyma cells, apoplastic phloem loading for partitioning into sink tissues, and phloem-based recirculation to the root. The central transporters involved in these processes in A. thaliana belong to two distinct clades of the Oligopeptide Transporter (OPT) family: the Yellow Stripelike1 (YSL) proteins and OPTs, for which the family was named (DiDonato et al., 2004; Schaaf et al., 2005; Waters et al., 2006; Curie et al., 2009; Lubkowitz, 2011). YSLs are proposed to be involved in the long-distance transport of transition metals, primarily $\mathrm{Fe}, \mathrm{Cu}$, and $\mathrm{Zn}$, associated with a strong metal ligand, nicotianamine (NA; DiDonato et al., 2004; Schaaf et al., 2005; Waters et al., 2006; Chu et al., 2010). Based on the expression of AtYSL2 in xylem parenchyma cells and its involvement in $\mathrm{Fe}$ homeostasis in A. thaliana, YSL2 has been proposed to function in lateral $\mathrm{Fe}$ movement in the vasculature (DiDonato et al., 2004; Schaaf et al., 2005). The tissue expression studies and phenotypes of the single $y s l 1$ and the double $y$ sllysl3 mutant plants suggest that YSL1 and YSL3 play a redundant role in the delivery of $\mathrm{Fe}$, as well as $\mathrm{Cu}$ and $\mathrm{Zn}$, into seeds of A. thaliana (Waters et al., 2006; Chu et al., 2010). OPT3, a close relative of the YSLs and a member of the OPT family, contributes to Fe delivery to seeds and loss of this function is suggested to cause embryo lethality in the opt3-1 null mutant (Stacey et al., 2002, 2008; Mendoza-Cozatl et al., 2014; Zhai et al., 2014). Knockdown opt 3 mutants are viable but accumulate high levels of $\mathrm{Fe}$ in both shoots and roots while exhibiting deregulated systemic Fe signaling marked by constitutive expression of IRT1 and FRO2 (Stacey et al., 2008; Mendoza-Cozatl et al., 2014; Zhai et al., 2014). Based on the ability of OPTs to transport peptides in heterologous systems (for review see, Lubkowitz, 2011), OPT3 has been suggested to transport $\mathrm{Fe}$, chelated with a peptide-based ligand or Fe-NA complexes. It has been shown, however, that NA does not improve the ability of OPT3 to complement growth of Fe uptake deficient, the fet 3 fet 4 mutant of S. cerevisiae on Fe-limited medium, suggesting that OPT3 is involved in Fe transport and its contribution to Fe-NA transport has to be examined further (Wintz et al., 2003). Given that a ubiquitous tripeptide glutathione, GSH, is among the plausible OPT substrates, OPT3 was tested for the ability to transport GSH or Fe-GS complexes. However, regardless of whether studies were done in a heterologous system or in planta, OPT3 was not capable of transporting GSH (Mendoza-Cozatl et al., 2014; Zhai et al., 2014). Studies using Xenopus oocytes showed that OPT3 mediates uptake of $\mathrm{Fe}^{2+}$ and also $\mathrm{Cd}^{2+}$ in a time-dependent manner in medium lacking metal ligands, suggesting that OPT3 is a transition metal transporter (Zhai et al., 2014). Future studies should test, however, if the addition of potential $\mathrm{Fe}$ and/or Cd ligands would alter this transport capability of OPT3 in oocytes. It is also important to determine whether OPT3 transports naked ions in planta as well, or is also capable to transport ion-ligand complexes. Concerning the physiological function of OPT3, it has been shown that it is expressed in the phloem where it is located to companion cells, and functions in $\mathrm{Fe}^{2+}$ partitioning from sources (mature leaves) to sinks such as young leaves and seeds (Mustroph et al., 2009; Mendoza-Cozatl et al., 2014; Zhai et al., 2014). Finally, data from Zhai et al. (2014) suggest that OPT3 contributes to Fe recycling from the xylem and acts as a functional link between the xylem and the phloem.

The cytosolic concentration of $\mathrm{Fe}$ is controlled mainly through $\mathrm{Fe}$ release from or import into the vacuole. The $\mathrm{Mn} / \mathrm{Fe}$ exporters, NRAMP3 and NRAMP4 mediate retrieval of $\mathrm{Fe}$ from vacuoles and function of these transporters is particularly essential during germination (Thomine et al., 2003; Lanquar et al., 2005). Vacuolar Iron Transporter 1-like (VTL) proteins and a second ferroportin transporter in A. thaliana, FPN2, mediate Fe import into the vacuole (Kim et al., 2006; Morrissey et al., 2009; Gollhofer et al., 2014). Vacuolar Iron Transporter 1 (VIT1), is expressed in the vasculature of seedlings and developing seeds; vit1-1 plants are unable to properly store $\mathrm{Fe}$ in seeds and embryos, resulting in reduced fitness of seedlings on soils with alkaline $\mathrm{pH}$ levels (Kim et al., 2006; Roschzttardtz et al., 2009).

The route of $\mathrm{Fe}$ from the rhizosphere into plant roots and $\mathrm{Fe}$ movement throughout the plant involves $\mathrm{Fe}(\mathrm{II}) \leftrightarrow \mathrm{Fe}(\mathrm{III})$ oxidation $\leftrightarrow$ reduction steps and ligand exchange reactions. The predominant form of $\mathrm{Fe}$ in the rhizosphere, $\mathrm{Fe}(\mathrm{III})$, is reduced by ferric chelate reductases to $\mathrm{Fe}(\mathrm{II})$ prior entering the symplast in the root. $\mathrm{Fe}(\mathrm{II})$ must be then oxidized to $\mathrm{Fe}(\mathrm{III})$ in the xylem since the latter is a predominant oxidation state of $\mathrm{Fe}$ in the xylem sap (Larbi et al., 2010; Rellan-Alvarez et al., 2010). Fe(III) exists in the xylem sap predominantly as a tri-iron(III), tri-citrate complex (Rellan-Alvarez et al., 2010). Since the redox potential of the cytoplasm favors $\mathrm{Fe}$ (II) over $\mathrm{Fe}$ (III), it is likely that $\mathrm{Fe}(\mathrm{II})$ constitutes the labile Fe pool of the plant cell, including the cytoplasm of sieve elements in the phloem (Williams, 1982). Therefore, $\mathrm{Fe}(\mathrm{III})$ must be reduced before entering a symplast in the shoot and members of the FRO family might be responsible for this event. In this regard, FRO6 is expressed at high level in leaves and reduces $\mathrm{Fe}(\mathrm{III})$ to $\mathrm{Fe}(\mathrm{II})$ at the cell surface in green tissues and thus, might be involved in $\mathrm{Fe}(\mathrm{III})$ to $\mathrm{Fe}(\mathrm{II})$ reduction prior loading of $\mathrm{Fe}$ (II) into leaf cells (Feng et al., 2006; Mukherjee et al., 2006; Jain et al., 2014). However, Grillet et al. (2014) have shown recently that ferric reduction activity is not responsible for $\mathrm{Fe}(\mathrm{III})$ to $\mathrm{Fe}(\mathrm{II})$ reduction in pea embryos, which absorb Fe(III) as a complex with citrate and malate from maternal tissues (Grillet et al., 2014). They found that the reduction step in embryos is absolutely dependent on the efflux of ascorbate. Further, this group showed that a similar, ascorbate-dependent $\mathrm{Fe}(\mathrm{III})$ to $\mathrm{Fe}(\mathrm{II})$ reduction occurs in embryos of $A$. thaliana 
(Grillet et al., 2014). Rellán-Álvarez et al. (2008) has shown that at $\mathrm{pH} 5.5$ and 7.5, Fe-citrate undergoes exchange reactions with NA. This group suggested that at the more neutral $\mathrm{pH}$ of the cytosol and the phloem sap, the Fe(II)-NA complex prevails. In contrast, the tri-Fe(III) tri-citrate complex is the prevailing form of $\mathrm{Fe}$ in more acidic conditions in the xylem sap, apoplast, and the vacuole.

\section{Local and Systemic Signaling of Fe Status}

\section{The Role of Fe Availability in Local and Systemic Signaling}

Iron bioavailability has been suggested to play a dual role in signaling: it acts as a positive regulator in local Fe deficiency responses but as a negative regulator in systemic deficiency responses. With regard to local regulation, Vert et al. (2003) have suggested that the pool of available Fe in the root apoplast controls the expression of IRT1 and FRO2 in A. thaliana. They found that the low concentration of $\mathrm{Fe}$ in the apoplast caused by prolonged Fe deficiency stops transcript accumulation of IRT1 and FRO2. This response is reversed when Fe-starved plants are resupplied with $\mathrm{Fe}$. In addition to apoplastic regulation, the concentration of $\mathrm{Fe}$ in the cytosol regulates induction of IRT1 and FRO2. In this regard, vacuolar membrane-localized NRAMP3 and IREG2/FPN2 influence IRT1 and FRO2 expression by controlling the vacuolar/cytosol $\mathrm{Fe}$ ratio in $A$. thaliana (Thomine et al., 2003; Lanquar et al., 2005). Thomine et al. (2003) showed that ectopic overexpression of NRAMP3 downregulates the expression of FRO2/IRT1 in A. thaliana likely due to enhanced cellular Fe availability via vacuolar Fe release (Thomine et al., 2003; Lanquar et al., 2005). Although results from ectopic overexpression may not reflect a physiological role of NRAMP3, this example is used to highlight the role of cytosolic Fe pools in the regulation of Fe deficiency responses in the root. Delayed induction of IRT1 and lower ferric chelate reductase activity was reported in fpn2-1 mutants, which lack the vacuolar transporter IREG2/FPN2 (Morrissey et al., 2009). The late response in mutant plants was suggested to be due to the excess of Fe in the cytoplasm (Morrissey et al., 2009).

With respect to long-distance signaling, it has been suggested that the concentration of $\mathrm{Fe}$ in the phloem might play a signaling role in the shoot-to-root communication of Fe demands (Maas et al., 1988). Maas et al. (1988) showed that phloem sap of Fedeficient castor oil (Ricinus communis) has lower concentration of $\mathrm{Fe}$ and roots have increased proton extrusion and ferric reductase activities, which could be reversed by the application of Fe to the leaves or by the transfer of whole plants to Fe-containing nutrient solution (Maas et al., 1988). The authors suggested that the capacity of the phloem to carry Fe to the root is sufficient to influence its Fe deficiency responses; the authors proposed that the Fe-related signal plays a repressive role in the phloem (Maas et al., 1988). Significant progress in understanding the role of $\mathrm{Fe}$ in systemic Fe signaling has been made using opt3-2 and opt3-3 mutants of $A$. thaliana (Stacey et al., 2008; MendozaCozatl et al., 2014; Zhai et al., 2014) and Table 1. Both mutant alleles accumulate high levels of Fe in shoots, while exhibiting constitutive Fe starvation phenotypes. Zhai et al. (2014) have shown that grafting of wild-type shoots onto opt3-3 roots rescues the constitutive Fe deficiency phenotype of the root. Consistently, Mendoza-Cozatl et al. (2014) have found that ectopic expression of OPT3 in the shoot of the opt3-2 mutant complements the opt3-2 mutant phenotype. Together, these studies indicate that OPT3 function in the shoot regulates $\mathrm{Fe}$ deficiency responses of the root. Studies using Xenopus oocytes showed that OPT3 mediates uptake of $\mathrm{Fe}^{2+}$ in a time-dependent manner in medium lacking metal ligands (Zhai et al., 2014). Consistent with the role of OPT3 in loading Fe into the phloem, Zhai et al. (2014) found that the concentration of $\mathrm{Fe}$ in the phloem sap of the opt3-3 mutant is significantly lower than in the wild-type. Given that the opt3-3 mutant overexpresses IRT1 and FRO2 in the root even under Fe-sufficient conditions, the lower Fe concentration in the phloem sap of the mutant substantiates the hypothesis that $\mathrm{Fe}$ concentration in the phloem plays an essential and inhibitory role in regulating Fe deficiency responses in the root. The inability of opt 3 mutants to load Fe into the phloem in leaves for the long-distance transport to sinks also explains the failure of foliar application of $\mathrm{Fe}$ to rescue the constitutive $\mathrm{Fe}$ deficiency responses of roots of opt 3 mutant alleles (Garcia et al., 2013). It is noteworthy that the concentration of $\mathrm{Fe}$ in the xylem of the opt3-3 mutant is 40 -fold higher than in the xylem of wild-type, suggesting that OPT3 mediates Fe recirculation from the xylem to the phloem via xylem-to-phloem transfer for subsequent phloem-based partitioning into sinks (Zhai et al., 2014).

Expression of OPT3 in roots is very low under standard condition but increases significantly under Fe deficiency (Zhai et al., 2014), raising a question of what is the role of OPT3mediated xylem-to-phloem transfer in Fe-deficient roots. Given the repressive role of the phloem $\mathrm{Fe}$ on expression of $\mathrm{Fe}$ uptake genes in roots, it is possible that OPT3-mediated transfer of $\mathrm{Fe}$ from the xylem to the phloem is needed to fine-tune Fe deficiency responses to prevent excessive Fe uptake and partitioning to the shoot (Figure 2). It would be interesting to test if expression of OPT3 in the root of the opt3 mutant would alter its transcriptional Fe deficiency responses. It is likely, however, that OPT3 function in the shoot in loading Fe into the phloem and partitioning into sinks is central to systemic Fe deficiency signaling.

Similar to opt3 mutant alleles of Arabidopsis, $d g l$ and $b r z$ mutants of pea accumulate more $\mathrm{Fe}$ in leaves, have increased expression of Fe acquisition genes, and a defect in remobilizing Fe from older to younger leaves (Kneen et al., 1990; Grusak and Pezeshgi, 1996; Garcia et al., 2013) and Table 1. Foliar application of $\mathrm{Fe}$ to the $d g l$ mutant does not downregulate expression of PsIRT1and PsFRO1, suggesting that similar to opt3 mutants of $A$. thaliana, the $d g l$ mutant cannot move Fe or Fe-related signal into the phloem (Garcia et al., 2013). Due to the similarity of phenotypes, it is possible that $d g l$ is an OPT3 ortholog. In contrast, application of Fe onto leaves of the brz mutant suppresses constitutive expression of PsFRO2 and PsIRT1, suggesting that brz is able to move an Fe-related signal into the phloem (Garcia et al., 2013). Future studies on $d g l$ and 
TABLE 1 | Description of mutant alleles exhibiting de-regulated iron (Fe) signaling.

\begin{tabular}{|c|c|c|c|c|c|c|}
\hline $\begin{array}{l}\text { Organism/ } \\
\text { Gene (allele) }\end{array}$ & Function & $\begin{array}{l}\text { Cellular } \\
\text { localization/tissue } \\
\text { expression }\end{array}$ & $\begin{array}{l}\text { Expression of } \\
\text { FRO2/IRT1 }\end{array}$ & $\begin{array}{l}\text { Fe concentration in the } \\
\text { mutant vs. wild-type }\end{array}$ & $\begin{array}{l}\text { Treatments that rescue } \\
\text { Fe deficiency symptoms }\end{array}$ & Reference \\
\hline $\begin{array}{l}\text { Arabidopsis } \\
\text { thaliana /FRD3 } \\
\text { (frd3) }\end{array}$ & Citrate efflux & $\begin{array}{l}\text { Plasma membrane/ } \\
\text { Root pericycle }\end{array}$ & $\begin{array}{l}\text { Constitutive } \\
\text { expression of } F R O 2 \\
\text { and IRT1 }\end{array}$ & $\begin{array}{l}\text { High Fe accumulation in } \\
\text { apoplast and vasculature, } \\
\text { but less Fe in cytosol }\end{array}$ & $\begin{array}{l}\text { Foliar application of Fe; } \\
\text { grafting frd3 shoots onto } \\
\text { Wt roots; citrate addition to } \\
\text { growth media }\end{array}$ & $\begin{array}{l}\text { Rogers and } \\
\text { Guerinot, 2002; } \\
\text { Green and Rogers, } \\
\text { 2004; Garcia et al., } \\
2013\end{array}$ \\
\hline $\begin{array}{l}\text { A. thaliana } \\
\text { /NAS1, NAS2 } \\
\text { NAS3, NAS4 } \\
\text { (nas } 4 x-1 \\
\text { nas } 4 x-2 \text { ) }\end{array}$ & $\begin{array}{l}\text { nicotianamine } \\
\text { (NA) synthesis }\end{array}$ & $\begin{array}{l}\text { Cytosol/ } \\
\text { Roots }(N A S 1 / 2) \text { and shoots } \\
(N A S 1 / 2 / 3 / 4)\end{array}$ & $\begin{array}{l}\text { Elevated expression } \\
\text { of } F R O 2, I R T 1 \text {, and } \\
\text { FIT in Fe-sufficient } \\
\text { plants in the nas } 4 x-1\end{array}$ & $\begin{array}{l}\text { Elevated Fe concentration } \\
\text { in the whole rosette of the } \\
\text { nas } 4 x-1 \text { mutant compared } \\
\text { at the reproductive but not } \\
\text { at the vegetative stage. } \\
\text { Higher Fe in older leaves } \\
\text { vs. younger leaves in the } \\
\text { nas } 4 x-1 \text { mutant }\end{array}$ & $\begin{array}{l}\text { Foliar application of Fe or } \\
\text { NA rescues interveinal leaf } \\
\text { chlorosis of nas } 4 x-2\end{array}$ & $\begin{array}{l}\text { Bauer et al., 2004; } \\
\text { Klatte et al., 2009; } \\
\text { Schuler et al., } 2012\end{array}$ \\
\hline $\begin{array}{l}\text { A. thaliana } \\
\text { /OPT3 } \\
\text { (opt3-2 and } \\
\text { opt3-3) }\end{array}$ & Fe influx & $\begin{array}{l}\text { Plasma membrane/ } \\
\text { Phloem companion cells }\end{array}$ & $\begin{array}{l}\text { Constitutive } \\
\text { expression of } F R O 2 \\
\text { and IRT1 }\end{array}$ & $\begin{array}{l}\text { High Fe accumulation in } \\
\text { shoots } \\
\text { Higher Fe in older leaves } \\
\text { vs. younger leaves }\end{array}$ & $\begin{array}{l}\text { Grafting Wt shoots onto } \\
\text { opt3 roots } \\
\text { Expression of OPT3 in } \\
\text { leaves of the opt3-2 }\end{array}$ & $\begin{array}{l}\text { Stacey et al., 2008; } \\
\text { Mendoza-Cozatl } \\
\text { et al., 2014; Zhai } \\
\text { et al., } 2014\end{array}$ \\
\hline $\begin{array}{l}\text { A. thaliana } \\
\text { MSL1, YSL2, } \\
\text { YSL3(ys/1,ysl2 } \\
\text { ys/1ys/3) }\end{array}$ & $\begin{array}{l}\text { Fe-NA } \\
\text { transport }\end{array}$ & $\begin{array}{l}\text { Plasma membrane/ } \\
\text { Vascular parenchyma cells } \\
\text { (YSL1 and YSL3), xylem } \\
\text { parenchyma cells in roots } \\
\text { (YSL2) }\end{array}$ & $\begin{array}{l}\text { Lower or wild-type } \\
\text { FRO2 activity in } \\
\text { ys/1ys/3 mutants, not } \\
\text { tested in ys/1 or ys/2 } \\
\text { mutants }\end{array}$ & $\begin{array}{l}\text { No difference in ys/2-1 } \\
\text { mutant } \\
\text { Less Fe in seeds of } y s / 1 \\
\text { single mutant } \\
\text { Less Fe in roots and shoots } \\
\text { of } y \text { s/1ys/3 double mutants }\end{array}$ & $\begin{array}{l}\text { Foliar application of Fe } \\
\text { increasing Fe in growth } \\
\text { media for detached roots }\end{array}$ & $\begin{array}{l}\text { DiDonato et al., } \\
\text { 2004; Jean et al., } \\
\text { 2005; Waters et al., } \\
\text { 2006; Chu et al., } \\
2010\end{array}$ \\
\hline $\begin{array}{l}\text { Solanum } \\
\text { Iycopersicon } \\
\text { NAS (chln) }\end{array}$ & NA synthesis & $\begin{array}{l}\text { Cytosol/ } \\
\text { Roots and shoots }\end{array}$ & $\begin{array}{l}\text { Constitutive } \\
\text { expression of SIFRO1 } \\
\text { and SIIRT1 }\end{array}$ & $\begin{array}{l}\text { High Fe accumulation in } \\
\text { shoots } \\
\text { Higher Fe in older leaves } \\
\text { vs. younger leaves }\end{array}$ & $\begin{array}{l}\text { Foliar application of Fe or } \\
\text { NA }\end{array}$ & $\begin{array}{l}\text { Scholz et al., 1985; } \\
\text { Garcia et al., } 2013\end{array}$ \\
\hline Unknown (brz) & Unknown & Unknown & $\begin{array}{l}\text { Constitutive } \\
\text { expression of } \\
\text { PSFRO1 and PSIRT1 }\end{array}$ & $\begin{array}{l}\text { High Fe accumulation in } \\
\text { shoots } \\
\text { Higher Fe in older leaves } \\
\text { vs. younger leaves }\end{array}$ & Foliar application of Fe & $\begin{array}{l}\text { Kneen et al., 1990; } \\
\text { Garcia et al., } 2013\end{array}$ \\
\hline Unknown (dgl) & Unknown & Unknown & $\begin{array}{l}\text { Constitutive } \\
\text { expression of } \\
\text { PSFRO1 and PSIRT1 }\end{array}$ & $\begin{array}{l}\text { High Fe accumulation in } \\
\text { older leaves }\end{array}$ & $\begin{array}{l}\text { Grafting Wt shoots onto dgl } \\
\text { roots }\end{array}$ & $\begin{array}{l}\text { Grusak and } \\
\text { Pezeshgi, 1996; } \\
\text { Garcia et al., } 2013\end{array}$ \\
\hline
\end{tabular}

$b r z$ are needed to understand the contribution of these genes to shoot-to-root communication of Fe status.

Bashir et al. (2015) have recently characterized an OPT3 ortholog in Oryza sativa, OsOPT7. This group have found that similar to AtOPT3, OsOPT7 is upregulated by Fe deficiency in both roots and shoots, and its translational product localizes to the plasma membrane. Further, the opt7-1 mutant exhibits upregulated expression of Fe-deficiency responsive genes while hyperaccumulating $\mathrm{Fe}$ in shoots even under Fe replete conditions. Unlike opt3 mutant alleles of $A$. thaliana, the constitutive transcriptional Fe-deficiency response of the opt7-1 mutant was observed mainly in shoots, not roots. The authors suggested that foliar $\mathrm{Fe}$ in the opt7-1 mutant is unavailable for the distribution, resulting in a local foliar Fe-deficiency response (Bashir et al., 2015). In contrast to AtOPT3, OsOPT7 seems to not to be involved in shoot-to-root communication of Fe status. Additionally, OsOPT7 does not functionally complement the fet3fet4 Fe uptake mutant of $S$. cerevisiae and does not confer transport of $\mathrm{Fe}^{2+}$ or $\mathrm{Fe}$ (III)-NA or $\mathrm{Fe}(\mathrm{II})$ complexed with the phytosiderophore 2'-deoxymugineic acid (DMA) in Xenopus oocytes. Whether the function of OsOPT7 is compromised in the heterologous system or it transports other substrates, is yet to be determined.

\section{Crosstalk Between Different Elements in Iron Deficiency Signaling}

The total metal composition of cells, the metallome, is very complex. Further, transition metals favor similar coordination geometries and ligand preferences (Haas and Franz, 2009). Therefore, among the overarching questions in the field is how the specificity and selectivity of metal sensing and signaling is achieved. Evidence from structural and biochemical studies of bacterial metal sensing systems have shown that selectivity and specificity of binding is determined by the metal binding properties of the ligand (such as affinity, measured as $\mathrm{K}_{d}$ ) and by the metal availability in the cytosol (metal access; Giedroc and Arunkumar, 2007; Waldron et al., 2009; Helmann, 2014). For example, since transition metals bind to their ligands with a $\mathrm{K}_{d}$ that generally follows the Irving-Williams series $(\mathrm{Pd}>\mathrm{Cu}>\mathrm{Ni}>\mathrm{Co}>\mathrm{Zn}>\mathrm{Cd}>\mathrm{Fe}>\mathrm{Mn}>\mathrm{Mg}$; Irving and Williams, 1953), equimolar concentrations of $\mathrm{Fe}, \mathrm{Cu}$, and $\mathrm{Zn}$ would result in selection of $\mathrm{Cu}$ and $\mathrm{Zn}$ for metal ligands 


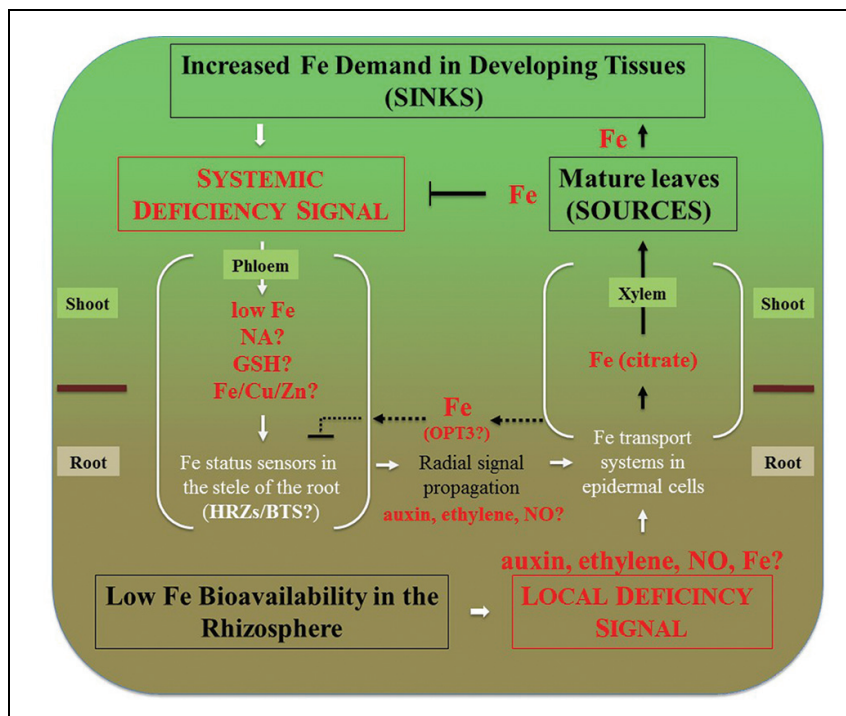

FIGURE 2 | Integration of local and systemic regulation of Fe deficiency responses in dicots. Systemic signaling is thought to be initiated in sink tissues such as young leaves, developing reproductive organs and seeds. Signal is transmitted to roots via the phloem. Decreased concentration of $\mathrm{Fe}$, or the ratio of $\mathrm{Fe}$ to other elements such as $\mathrm{Zn}, \mathrm{Cu}$, as well as NA itself have been considered to play a role in systemic signaling. While Fe has been considered to act as a repressive signal, the generation of a promotive signal that is propagated from shoots to roots via the phloem has been suggested as well (Enomoto and Goto, 2008). These signals are then percepted in the vasculature of roots and radially transmitted toward root epidermal cells that respond by increased expression of Fe uptake and root-to-shoot partitioning systems. Local signaling events are initiated by the fluctuation of Fe bioavailability in the rhizosphere and result in upregulation of Fe uptake and root-to-shoot partitioning transport systems. We note that Fe itself is essential for the expression of local Fe deficiency responses. For example, Vert et al. (2003) have shown that prolonged Fe deficiency stops expression of IRT1 and $F R O 2$ in $A$. thaliana and this transcriptional response is restored by $\mathrm{Fe}$ supplementation of Fe-starved plants. Therefore, low Fe bioavailability in the rhizosphere depicts the situation where Fe concentration in the apoplast is sufficient to induce Fe deficiency responses. Fe delivery to sources (mature leaves) via xylem and subsequent Fe loading into the phloem downregulates systemic signaling and might override local Fe deficiency signaling. For example, the severely repressed lateral root elongation in response to local $\mathrm{Fe}$ supply in the irt1 mutant of $A$. thaliana can be circumvented by the application of Fe to the shoot (Giehl et al., 2012). Dashed lines represent putative interactions between the xylem and the phloem in the root that might be mediated by OPT3 to fine-tune crosstalk between local and systemic signaling to prevent excessive Fe accumulation. Under Fe deficiency, roots increase the production of ethylene and $\mathrm{NO}$ that might serve in the radial propagation of the signal, as well as mediate local signaling.

and/or sensors over Fe. However, the situation in vivo is much more complex and the accessibility of elements is controlled by metal uptake and redistribution in subcellular compartments (Blaby-Haas and Merchant, 2014). As a result, concentrations of $\mathrm{Cu}$ and $\mathrm{Zn}$ in the symplast of plants are orders of magnitude lower than Fe (Table 2) explaining why strongLMW ligands for transition metals such as NA in non-graminaceous plants, is associated preferentially with Fe but not $\mathrm{Cu}$ or $\mathrm{Zn}$ in the symplast under standard growth conditions. However, a different scenario might occur under Fe deficiency, which alters the metallome of different species including plants. The most common metallome response of $A$. thaliana to Fe deficiency includes an increase in the concentrations of $\mathrm{Mn}, \mathrm{Co}, \mathrm{Zn}$, and $\mathrm{Cd}$ and decrease in the concentration of Mo (Baxter et al., 2008). In addition, it has been shown that the concentration of $\mathrm{Cu}$ doubles in the rosette leaves of Fe-deficient $A$. thaliana within $24 \mathrm{~h}$ of switching plants to Fe-deficient nutrient solution and that optimal $\mathrm{Cu}$ supply is required for Fe deficiency responses (Bernal et al., 2012; Waters et al., 2012; Waters and Armbrust, 2013). It is noteworthy that concentration of $\mathrm{Zn}, \mathrm{Cu}, \mathrm{Mn}$, and $\mathrm{Co}$ is significantly higher in shoots of the opt3-2 and opt3-3 mutants that exhibit constitutive Fe deficiency responses (Stacey et al., 2008; Zhai et al., 2014). Under these circumstances, Fe ligands and regulators might be mismetallated that, in turn, could be a contributing factor to $\mathrm{Fe}$ deficiency signaling.

In bacterial systems, non-cognate metals might be discriminated against because the ability of some metalloregulators to exert transcriptional changes is also determined by allostery and thus, only the correct metal bound in an optimal conformation to the metalloregulator can alter its DNA-binding capacity to regulate gene expression (Giedroc and Arunkumar, 2007; Waldron et al., 2009; Helmann, 2014). Whether similar regulatory events occur in plants is not yet explored. Notably, a positive regulator of $\mathrm{Fe}$ deficiency-responsive genes in rice, Iron Deficiency-responsive Element-binding Factor 1 (IDEF1) that was recently identified as a putative Fe-sensor, binds not only ionized Fe but also other divalent metals such as $\mathrm{Zn}^{2+}, \mathrm{Cu}^{2+}$, and $\mathrm{Ni}^{2+}$ (Kobayashi et al., 2012). Whether IDEF1 regulates expression of its targets via allosteric association with DNA is unknown. Nevertheless, based on these findings and the fact that Fe deficiency combined with deficiencies of other divalent metals mitigate the symptoms of Fe deficiency in tobacco (Kobayashi et al., 2003), it has been proposed that plant sensors might detect the cellular concentration ratio between $\mathrm{Fe}$ and other metals rather than their absolute concentration (Kobayashi and Nishizawa, 2014). In this regard, Ferric Uptake Regulator (Fur) in Bacillus subtilis senses Fe sufficiency, Manganese transport Regulator (MnR) senses Mn sufficiency, while a Fur homolog, PerR, senses the intracellular $\mathrm{Fe} / \mathrm{Mn}$ ratio for the subsequent transcriptional regulation of their targets (Helmann, 2014). In addition to IDEF1, two more recently identified putative Fe sensors from rice and $A$. thaliana, E3 ubiquitin ligases HRZs/BTS were found to bind not only $\mathrm{Fe}$ but also $\mathrm{Zn}$ ions and negatively regulate Fe acquisition under conditions of Fe sufficiency in both graminaceous and non-graminaceous plants (Kobayashi et al., 2013; Kobayashi and Nishizawa, 2015; Selote et al., 2015). Selote et al. (2015) have shown that Fe binding destabilizes HRZ/BTS in A. thaliana and proposed that HRZ/BTS adjusts Fe deficiency responses, ensuring sufficient but not excess Fe uptake into roots.

\section{Iron Ligands as Putative Signals}

Among the most recognized Fe ligands are citric acid, NA, and most recently GSH. These ligands have a wide range of affinities to $\mathrm{Fe}$ and other metals (Table 2), which determine 
TABLE 2 | Estimated concentrations of Fe, $\mathrm{Zn}$, and $\mathrm{Cu}$ in the cell and in the phloem sap and affinity constants ( $\left.\mathrm{K}_{d}\right)$ for the formation of the indicated metal-ligand complexes.

\begin{tabular}{|c|c|c|c|}
\hline & $\mathrm{Fe}^{2+}$ & $\mathrm{Zn}^{2+}$ & $\mathrm{Cu}^{2+}$ \\
\hline Cytoplasmic concentration (M) & $10^{-6}$ Kruszewski, 2004 & $\begin{array}{l}10^{-11} ; 10^{-12} \\
\text { Silva and Williams, } 2001 \\
\text { Bozym et al., } 2006 \\
0.4 \times 10^{-9} \\
\text { Lanquar et al., } 2014\end{array}$ & $\begin{array}{l}10^{-15} ;<10^{-18} \\
\text { Silva and Williams, 2001; } \\
\text { Kuchar and Hausinger, } 2004\end{array}$ \\
\hline Phloem sap concentration (M) & $1.7 \times 10^{-4}$ Marschner, 1995 & $\begin{array}{l}2.4 \times 10^{-4} \\
\text { Marschner, } 1995\end{array}$ & $\begin{array}{l}1.9 \times 10^{-5} \\
\text { Marschner, } 1995\end{array}$ \\
\hline Xylem sap concentration (M) & $10^{-5}$ Marschner, 1995 & $\begin{array}{l}2 \times 10^{-5} \\
\text { Marschner, } 1995\end{array}$ & $\begin{array}{l}1.7 \times 10^{-6} \\
\text { Marschner, } 1995\end{array}$ \\
\hline $\log K_{d}(N A)$ & 12.1 Callahan et al., 2006 & $\begin{array}{l}\text { 14.7/15.4 Callahan et al., } \\
2006\end{array}$ & $\begin{array}{l}18.6 \\
\text { Callahan et al., } 2006\end{array}$ \\
\hline $\log K_{d}(G S H)$ & 5.1 Hider and Kong, (2011) & $\begin{array}{l}12.5 \text { Martell and Smith, } 1974 \\
\text { for } \mathrm{ML}_{2} / \mathrm{M}^{2} \mathrm{~L}^{2}\end{array}$ & $\begin{array}{l}\text { 19.9* } \\
\text { Martell and Smith, } 1974 \\
\text { for } M(H L)_{2} / M .(H L)^{2}\end{array}$ \\
\hline Log $K_{d}$ (citrate) & 4.4 Callahan et al., 2006 & 5.0 Callahan et al., 2006 & 5.9 Callahan et al., 2006 \\
\hline
\end{tabular}

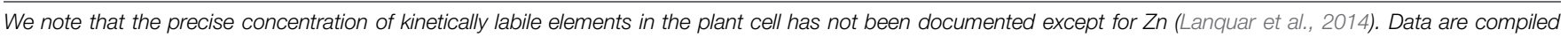

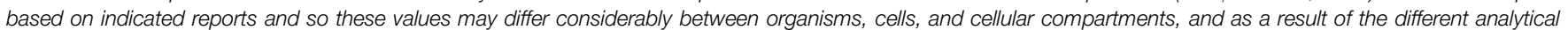
methods and conditions that have been employed.

* The stability constant was enumerated for $\mathrm{Cu}^{+}$.

their ligand exchange reactions and might influence Fe deficiency signaling.

\section{Citric Acid}

Citric acid has been proposed to be a preferred Fe ligand under acidic conditions of the vacuole, the xylem sap and the apoplast (Rellan-Alvarez et al., 2010). The important role of citrate in Fe-deficiency signaling has been documented by the characterization of $\mathrm{frd} 3$ mutants of $A$. thaliana with a nonfunctional citrate transporter gene (Rogers and Guerinot, 2002; Green and Rogers, 2004; Durrett et al., 2007) and Table 1. These mutants have $40 \%$ less citrate in the xylem than those of the wild-type, accumulate $\mathrm{Fe}$ in roots and shoots while manifesting the constitutive upregulation of IRT1 and FRO2 in roots (Rogers and Guerinot, 2002). Subsequent experiments have shown that the $f r d 3$ mutation leads to the retention of Fe in the apoplast of xylem vessels spanning the root-to-leaf vasculature leading to decreased Fe concentration in the symplast of leaf mesophyll cells (Green and Rogers, 2004; Roschzttardtz et al., 2011). As a result of Fe mislocalization in the frd 3 mutant, leaf cells experience Fe deficiency and signal to the root to increase expression of $\mathrm{Fe}$ uptake genes. Foliar application of Fe decreases the expression of IRT1 and FRO2 in the root of the frd3 mutant (Garcia et al., 2013) suggesting that a repressive Fe-related shoot-to-root signaling via the phloem is functional in these mutants. In addition to the indirect role of citrate in systemic Fe status signaling, citrate is regarded among the retrograde signals communicating changes in the metabolic status of mitochondria to the nucleus occurring under Fe deficiency (reviewed in, Vigani et al., 2013b).

\section{Nicotianamine}

The amino acid derivative, NA, serves as a preferred Fe ligand in the cytosol including the shoot-to-root phloem symplast continuum since the neutral $\mathrm{pH}$ values in these tissues favor the formation and stability of the Fe-NA complex (von Wiren et al., 1999; Rellán-Álvarez et al., 2008). NA is synthesized from $S$-adenosylmethionine in a reaction catalyzed by NA synthase (NAS), encoded by four NAS genes in A. thaliana (Ling et al., 1999). The physiological and genetic studies of the quadruple nas $4 x-1$ and nas $4 x-2$ mutants of $A$. thaliana and the tomato chln mutant provide evidence that NA is needed for systemic Fe status signaling (Table 1). At the vegetative stage, rosette leaves of the nas $4 x-1$ mutant allele have a significantly lower concentration of NA and a higher concentration of Fe, along with minor leaf chlorosis that intensifies during the transition from vegetative to reproductive growth (Klatte et al., 2009). Additionally, nas $4 x-1$ mutants have elevated expression levels of IRT1, FRO2, and FIT (encoding FER-like iron-deficiency-induced bHLH transcription factor, Bauer et al., 2007) in roots under Fe-replete conditions (Table 1 and Klatte et al., 2009). In contrast, the quadruple nas $4 x$ 2 mutant that does not synthesize NA shows strong leaf chlorosis and is sterile (Schuler et al., 2012). Schuler et al. (2012) have shown that Fe accumulates in the phloem of the nas $4 x$ - 2 mutant and the chlorotic phenotype of young leaves of nas $4 x-2$ can be rescued by NA application onto the leaf surface. From these experiments, Schuler et al. (2012) proposed that NA functions in Fe mobilization out of the phloem to sink organs. Whether NA rescues the constitutive Fe deficiency response in roots of the nas $4 x$ - 2 mutant has not been tested. However, given the role of NA in maintaining Fe bioavailability in the shoot-to-root symplast continuum, the decreased NA concentration in leaves of the nas $4 x-1$ mutant and elevated expression of IRT1, FRO2 and their regulator FIT in roots of plants grown under control conditions is consistent with the hypothesis that the decreased supply of bioavailable $\mathrm{Fe}$ into roots might be responsible for constitutive Fe deficiency responses of the root.

The tomato chloronerva (chln) mutant contains a defect in NAS as well (Ling et al., 1999) and similar to nas $4 x-1$ mutants, chln develops interveinal chlorosis, displays constitutive Fe uptake and hyperaccumulates Fe in shoots (Scholz et al., 1985; 
Pich and Scholz, 1996) and Table 1. The chlorotic phenotype of $c h l n$ is rescued by foliar application of NA, which also decreases constitutive Fe uptake (Scholz et al., 1985; Garcia et al., 2013). This effect of NA on the regulation of Fe uptake systems in roots is likely due to the role of NA in the recirculation of bioavailable $\mathrm{Fe}$ from shoots to roots and by aiding in Fe remobilization out of phloem vessels in the root for subsequent signal propagation toward epidermal cells to control Fe uptake (Figure 2).

With regard to the direct involvement of NA in local and systemic Fe status signaling, it was reported that frd 3 mutants with impaired root-to-shoot translocation of Fe-citrate, manifest a twofold higher NA levels in roots and shoots than the wildtype (Rogers and Guerinot, 2002). Schuler et al. (2012) suggested that citrate and NA act, in part, redundantly in the long-distance transport of $\mathrm{Fe}$ from roots to leaves. This however, does not exclude the possibility that NA itself may also act as a shoot-toroot promotive signal reporting on the Fe status of the shoot. It is noteworthy that given the complexity of the metallome of the phloem sap and $\mathrm{K}_{d}$ of NA for $\mathrm{Cu}^{2+}$ and $\mathrm{Zn}^{2+}$ (Table 2), it is unlikely that NA exists in the "apo" form in the frd3 plants. It is possible that recirculating NA complexed with $\mathrm{Cu}$ or $\mathrm{Zn}$, delivers latter metals instead of Fe to metalloregulators, altering their effects on the expression of Fe uptake genes in the root of the frd 3 plants (see Crosstalk between Different Elements in Iron Deficiency Signaling).

Nicotianamine might not be the only ligand in the phloem involved in the shoot-to-root communication of $\mathrm{Fe}$ status. For example, the double ysl1ysl3 mutant of $A$. thaliana lacks phloem-associated metal-NA transporters and has a decreased concentration of Fe in roots and shoots (Waters et al., 2006). However, the long-distance signaling is not altered in the ysllysl3 mutant: its exhibits a wild-type level of IRT1 and FRO2 expression unless is grown under Fe-deficient conditions. Further, the suppression of Fe deficiency responses in roots of the chln mutant by foliar application of Fe (Scholz et al., 1985; Garcia et al., 2013) points to the existence of other Fe ligand(s) that contribute to Fe solubility/bioavailability in the phloem resulting in the ability of Fe to exert its suppressive role. In this regard, a protein capable of binding to $\mathrm{Fe}$, iron transporter protein (ITP), was found in the phloem sap of $R$. communis (Krüger et al., 2002), and most recently, a metallothionein-like protein type $2 \mathrm{~B}$, and $\mathrm{a}$ low-molecular weight protein with similarity to a phloem-specific protein from Medicago truncatula, were identified associated with Fe in the phloem sap of Lupinus texensis (Lattanzio et al., 2013). However, their contribution to Fe homeostasis and signaling has not been yet examined.

\section{Glutathione}

The ubiquitous tripeptide glutathione $(\gamma$-glutamyl-cysteinylglycine, GSH) is an essential monothiol that is present in millimolar concentrations in the cell and is the major determinant of the cellular redox status in addition to its recognized function in the regulation of cell proliferation and xenobiotic detoxification (Noctor et al., 2012; Schnaubelt et al., 2015). Most recent studies in Saccharomyces cerevisiae and Schizosaccharomyces pombe uncovered the involvement of $\mathrm{GSH}$ in $\mathrm{Fe}$ metabolism and signaling through its role in the maturation of extra-mitochondrial Fe-S clusters (Sipos et al., 2002; Mühlenhoff et al., 2010; Hider and Kong, 2011, 2013; Kumar et al., 2011). Sipos et al. (2002) have shown that deletion of the gene encoding the enzyme that catalyzes the first step of GSH biosynthesis, GSH1 ( $\Delta g s h 1)$ leads to the growth arrest, the accumulation of high Fe concentrations in the mitochondria and the decrease in the maturation of $\mathrm{Fe}-\mathrm{S}$ proteins in the cytosol. GSH is suggested to protect $\mathrm{Fe}-\mathrm{S}$ clusters in small oxidoreductases, glutaredoxins (GRXs), that facilitate FeS cluster biosynthesis (Bandyopadhyay et al., 2008). Kumar et al. (2011) have shown that low or high GSH levels trigger an intense Fe starvation-like response in yeast cells and impair the activity of extra-mitochondrial Fe-S cluster containing enzymes. Further, these authors emphasized the role of GSH in Fe metabolism rather than in maintaining the redox state of yeast cells. Hider and Kong (2011) used speciation plots that consider typical cellular concentrations of potential Fe (II) ligands in the cytoplasm and stability constants for $\mathrm{Fe}(\mathrm{II})$ complexes to show that GSH dominates over other potential Fe ligands, such as citrate in the cytoplasm of yeast cells. These authors proposed that Fe (II)-GSH is a dominant cytoplasmic ferrous Fe pool in yeast. Furthermore, they suggested that association of Fe with GSH provides selectivity over other transition elements in providing substrate for Fe-S cluster assembly (Hider and Kong, 2011).

The role of GSH in Fe homeostasis and signaling in plants has not been comprehensively addressed but it has been shown that GSH is also important to maintain proper homeostasis and crosstalk between $\mathrm{Zn}$ and Fe metabolism in A. thaliana (Shanmugam et al., 2012). It is noteworthy, however, that role of GSH in Fe homeostasis in plants might be somewhat different from yeast, bacteria, and mammals because, unlike these organisms, plants synthesize $\mathrm{NA}$, which $\mathrm{K}_{d}$ for $\mathrm{Fe}(\mathrm{II})$ is orders of magnitude higher than that of Fe(II)-GSH (Table 2). Therefore, NA might dominate over GSH in the cytoplasm in plants. However, a different scenario might occur in subcellular compartments, particularly in mitochondria and chloroplasts both bearing high $\mathrm{Fe}$ and both responsible for $\mathrm{Fe}-\mathrm{S}$ cluster and heme synthesis (Balk and Schaedler, 2014). Furthermore, the first rate-limited step in GSH synthesis, namely formation of $\gamma$-EC, occurs exclusively in chloroplasts due to exclusive chloroplast localization of the first enzyme in GSH production, glutamate cysteine ligase (GSH1), and homozygous mutation in GSH1 is lethal (Wachter et al., 2005; Cairns et al., 2006). The second enzyme glutathione synthetase (GSH2) is located in both the cytosol and plastids and cytosolic form can rescue GSH1 lethality suggesting the translocation of $\gamma$-EC and GSH in and out of chloroplast (Pasternak et al., 2008). In vitro studies have shown that GSH is required for $\mathrm{Fe}-\mathrm{S}$ cluster assembly using chloroplast GrxS14 from poplar (Bandyopadhyay et al., 2008). However, much more studies are needed to shed light on the role of GSH in Fe homeostasis and signaling in these subcellular compartments.

With regard to the role of GSH in long-distance Fe signaling and homeostasis, Mendoza-Cozatl et al. (2014) have tested whether foliar application of GSH or Fe-glutathione complex would rescue the constitutive high activity of the root ferric reductase in the opt3-2 mutant. However, in all cases the activity of the root ferric reductase remained constitutively high in 
opt3-2 vs. wild-type, suggesting that shoot-to-root transport of GSH alone has little effect on the long-distance signaling of the Fe status at least with regard to OPT3 function in Arabidopsis. It is noteworthy, however, that we found that overaccumulation of Fe in leaves of the opt3-3 mutant is associated with twofold increase in the concentration of GSH compared to wild-type, both grown under Fe-sufficient conditions (Zhai, 2011). This suggests that GSH might be involved in buffering Fe concentration in leaf cells of the opt3 mutant.

\section{Concluding Remarks}

Despite significant progress in our understanding of the regulation of $\mathrm{Fe}$ homeostasis in plants, the exact nature of local and systemic Fe signals, their interactions with sensors in different tissues and cell types as well as the signal propagation from the vascular cylinder in roots to root epidermal cells to trigger Fe deficiency response, remain elusive. Here we discussed the current status of knowledge of the contribution of $\mathrm{Fe}$, transition metal ligands and interactions between metals in local and systemic Fe signaling. From the current outlook, studies of the ligand environment of $\mathrm{Fe}$, its distribution among different cellular compartments, the composition and metal interactions of potential Fe ligands in the phloem sap in Fe-signaling mutants will expand our knowledge of how Fe signaling is achieved.

Fe-sensors, HRZs/BTS, which are transcriptionally upregulated by $\mathrm{Fe}$ deficiency in root pericycle in A. thaliana and in the stele in rice (Long et al., 2010; Kobayashi et al., 2013) might be involved in the perception of the phloemderived Fe signal. In addition, plant hormones, auxin, ethylene, abscisic acid, gibberellin, brassinosteroids, and nitric oxide, not discussed here, have been reported to act as positive regulators of Fe deficiency (reviewed in, Hindt and Guerinot,

\section{References}

Balk, J., and Schaedler, T. A. (2014). Iron cofactor assembly in plants. Annu. Rev. Plant Biol. 65, 125-153. doi: 10.1146/annurev-arplant-050213-35759

Bandyopadhyay, S., Gama, F., Molina-Navarro, M. M., Gualberto, J. M., Claxton, R., Naik, S. G., et al. (2008). Chloroplast monothiol glutaredoxins as scaffold proteins for the assembly and delivery of [2Fe-2S] clusters. EMBO J. 27, 1122-1133.

Bashir, K., Ishimaru, Y., Itai, R. N., Senoura, T., Takahashi, M., An, G., et al. (2015). Iron deficiency regulated OsOPT7 is essential for iron homeostasis in rice. Plant Mol. Biol. 88, 165-176. doi: 10.1007/s11103-015-0315-0

Bauer, P., Ling, H.-Q., and Guerinot, M. L. (2007). FIT, the FER-LIKE IRON DEFICIENCY INDUCED TRANSCRIPTION FACTOR in Arabidopsis. Plant Physiol. Biochem. 45, 260-261. doi: 10.1016/j.plaphy.2007. 03.006

Bauer, P., Thiel, T., Klatte, M., Bereczky, Z., Brumbarova, T., Hell, R., et al. (2004). Analysis of sequence, map position, and gene expression reveals conserved essential genes for iron uptake in Arabidopsis and tomato. Plant Physiol. 136, 4169-4183. doi: 10.1104/pp.104.047233

Baxter, I. R., Vitek, O., Lahner, B., Muthukumar, B., Borghi, M., Morrissey, J., et al. (2008). The leaf ionome as a multivariable system to detect a plant's physiological status. Proc. Natl. Acad. Sci. U.S.A. 105, 12081-12086. doi: 10.1073/pnas.0804175105

Bernal, M., Casero, D., Singh, V., Wilson, G. T., Grande, A., Yang, H., et al. (2012). Transcriptome sequencing identifies spl7-regulated copper acquisition genes
2012; Wang et al., 2012; Kobayashi and Nishizawa, 2014). Of these, ethylene and NO, which level increases in roots under Fe deficiency are among the plausible candidates of radial signal propagation from the vasculature to the root epidermal cells (Figure 2). It has been shown that exogenous application of 1-Aminocyclopropane-1-carboxylic acid (ACC, ethylene precursor) or $S$-nitrosoglutathione (GSNO, $\mathrm{NO}$ donor) to $\mathrm{Fe}$ deficient plants up-regulates the expression of $\mathrm{Fe}$-acquisition genes, but this effect does not occur in Fe-deficient plants sprayed with Fe (Garcia et al., 2013), suggesting that ethylene and $\mathrm{NO}$ act downstream of the phloem-derived repressive $\mathrm{Fe}$ signal.

Another important area deals with metabolic adjustments and crosstalk between mitochondria and chloroplast caused by changes in Fe bioavailability. Fe is required for heme and $\mathrm{Fe}-\mathrm{S}$ clusters synthesis with both processes occurring in mitochondria and chloroplasts. Therefore, both compartments compete for labile Fe pools and are implicated in the retrograde Fe deficiency signaling (Vigani et al., 2013a,b). However, we are still far from understanding the nature of mitochondria- and chloroplastderived signals and how these signals are integrated to maintain Fe status of plants. Further studies of the signaling mechanisms that plants use to coordinate Fe demand with Fe uptake, transport and tissue partitioning will facilitate molecular breeding efforts directed on improving crop yield on marginal soils and increasing Fe concentration in edible plant organs to improve human nutrition and health.

\section{Acknowledgments}

Work in OV lab is supported by the National Institute of Food and Agriculture, U.S. Department of Agriculture, Hatch under 2014-15-151.

fro4/fro5 and the copper dependence of iron homeostasis in Arabidopsis. Plant Cell 24, 738-761. doi: 10.1105/tpc.111.090431

Bienfait, H. F., Van Den Briel, W., and Mesland-Mul, N. T. (1985). Free space iron pools in roots: generation and mobilization. Plant Physiol. 78, 596-600. doi: $10.1104 /$ pp.78.3.596

Blaby-Haas, C. E., and Merchant, S. S. (2014). Lysosome-related organelles as mediators of metal homeostasis. J. Biol. Chem. 289, 28129-28136. doi: 10.1074/jbc.R114.592618

Bozym, R. A., Thompson, R. B., Stoddard, A. K., and Fierke, C. A. (2006). Measuring picomolar intracellular exchangeable zinc in pc-12 cells using a ratiometric fluorescence biosensor. ACS Chem. Biol. 1, 103-111. doi: 10.1021/cb500043a

Cairns, N. G., Pasternak, M., Wachter, A., Cobbett, C. S., and Meyer, A. J. (2006). Maturation of Arabidopsis seeds is dependent on glutathione biosynthesis within the embryo. Plant Physiol. 141, 446-455. doi: 10.1104/pp.106.077982

Callahan, D. L., Baker, A. J., Kolev, S. D., and Wedd, A. G. (2006). Metal ion ligands in hyperaccumulating plants. J. Biol. Inorg. Chem. 11, 2-12. doi: 10.1007/s00775-005-0056-57

Chu, H. H., Chiecko, J., Punshon, T., Lanzirotti, A., Lahner, B., Salt, D. E., et al. (2010). Successful reproduction requires the function of Arabidopsis yellow stripe-like1 and yellow Stripe-Like3 metal-nicotianamine transporters in both vegetative and reproductive structures. Plant Physiol. 154, 197-210. doi: 10.1104/pp.110.159103

Curie, C., Cassin, G., Couch, D., Divol, F., Higuchi, K., Le Jean, M., et al. (2009). Metal movement within the plant: contribution of nicotianamine 
and yellow stripe 1-like transporters. Ann. Bot. 103, 1-11. doi: 10.1093/aob/ $\operatorname{mcn} 207$

DiDonato, R. J., Roberts, L. A., Sanderson, T., Eisley, R. B., and Walker, E. L. (2004). Arabidopsis Yellow Stripe-Like2 (YSL2): a metal-regulated gene encoding a plasma membrane transporter of nicotianamine-metal complexes. Plant J. 39, 403-414. doi: 10.1111/j.1365-313X.2004.02128.x

Durrett, T. P., Gassmann, W., and Rogers, E. E. (2007). The FRD3-mediated efflux of citrate into the root vasculature is necessary for efficient iron translocation. Plant Physiol. 144, 197-205. doi: 10.1104/pp.107.097162

Eide, D., Broderius, M., Fett, J., and Guerinot, M. L. (1996). A novel iron-regulated metal transporter from plants identified by functional expression in yeast. Proc. Natl. Acad. Sci. U.S.A. 93, 5624-5628. doi: 10.1073/pnas.93.11.5624

Enomoto, Y., and Goto, F. (2008). Long-distance signaling of iron deficiency in plants. Plant Signal. Behav. 3, 396-397. doi: 10.4161/psb.3.6.5419

Feng, H., An, F., Zhang, S., Ji, Z., Ling, H. Q., and Zuo, J. (2006). Light-regulated, tissue-specific, and cell differentiation-specific expression of the Arabidopsis Fe(III)-chelate reductase gene AtFRO6. Plant Physiol. 140, 1345-1354.

Fourcroy, P., Sisó-Terraza, P., Sudre, D., Savirón, M., Reyt, G., Gaymard, F., et al. (2014). Involvement of the ABCG37 transporter in secretion of scopoletin and derivatives by Arabidopsis roots in response to iron deficiency. New Phytol. 201, 155-167. doi: 10.1111/nph.12471

Garcia, M. J., Romera, F. J., Stacey, M. G., Stacey, G., Villar, E., Alcantara, E., et al. (2013). Shoot to root communication is necessary to control the expression of iron-acquisition genes in Strategy I plants. Planta 237, 65-75. doi: 10.1007/s00425-012-1757-0

Giedroc, D. P., and Arunkumar, A. I. (2007). Metal sensor proteins: nature's metalloregulated allosteric switches. Dalton Trans. 63, 3107-3120. doi: 10.1039/b706769k

Giehl, R. F. H., Lima, J. E., and Von Wirén, N. (2012). Localized iron supply triggers lateral root elongation in Arabidopsis by altering the aux1-mediated auxin distribution. Plant Cell 24, 33-49. doi: 10.1105/tpc.111.092973

Gollhofer, J., Timofeev, R., Lan, P., Schmidt, W., and Buckhout, T. J. (2014). Vacuolar-iron-transporter1-like proteins mediate iron homeostasis in Arabidopsis. PLoS ONE 9:e110468. doi: 10.1371/journal.pone.0110468

Green, L. S., and Rogers, E. E. (2004). FRD3 controls iron localization in Arabidopsis. Plant Physiol. 136, 2523-2531. doi: 10.1104/pp.104.045633

Grillet, L., Ouerdane, L., Flis, P., Hoang, M. T. T., Isaure, M.-P., Lobinski, R., et al. (2014). Ascorbate efflux as a new strategy for iron reduction and transport in plants. J. Biol. Chem. 289, 2515-2525. doi: 10.1074/jbc.M113.514828

Grusak, M. (1995). Whole -root iron(III)-reductase activity throughout the life cycle of iron-grown Pisum sativum L. (Fabaceae): relevance to the iron nutrition of developing seeds. Planta 197, 111-117. doi: 10.1007/bf00239946

Grusak, M. A., and Pezeshgi, S. (1996). Shoot-to-root signal transmission regulates root fe(iii) reductase activity in the dgl mutant of pea. Plant Physiol. 110, 329-334.

Haas, K. L., and Franz, K. J. (2009). Application of metal coordination chemistry to explore and manipulate cell biology. Chem. Rev. 109, 4921-4960. doi: $10.1021 / \mathrm{cr} 900134 \mathrm{a}$

Helmann, J. D. (2014). Specificity of metal sensing: iron and manganese homeostasis in Bacillus subtilis. J. Biol. Chem. 289, 28112-28120. doi: $10.1074 /$ jbc.R114.587071

Hider, R., and Kong, X. (2011). Glutathione: a key component of the cytoplasmic labile iron pool. Biometals 24, 1179-1187. doi: 10.1007/s10534-011-9476-8

Hider, R. C., and Kong, X. (2013). Iron speciation in the cytosol: an overview. Dalton Trans. 42, 3220-3229. doi: 10.1039/c2dt32149a

Hindt, M. N., and Guerinot, M. L. (2012). Getting a sense for signals: regulation of the plant iron deficiency response. Biochim. Biophys. Acta 1823, 1521-1530. doi: 10.1016/j.bbamcr.2012.03.010

Irving, H., and Williams, R. J. P. (1953). The stability of transition-metal complexes. J. Chem. Soc. 3, 3192-3210. doi: 10.1039/Jr9530003192

Ishimaru, Y., Kakei, Y., Shimo, H., Bashir, K., Sato, Y., Sato, Y., et al. (2011). A rice phenolic efflux transporter is essential for solubilizing precipitated apoplasmic iron in the plant stele. J. Biol. Chem. 286, 24649-24655. doi: 10.1074/jbc.M111.221168

Jain, A., Wilson, G. T., and Connolly, E. L. (2014). The diverse roles of FRO family metalloreductases in iron and copper homeostasis. Front. Plant Sci. 5:100. doi: 10.3389/fpls. 2014.00100
Jean, M. L., Schikora, A., Mari, S., Briat, J.-F., and Curie, C. (2005). A loss-offunction mutation in AtYSL1 reveals its role in iron and nicotianamine seed loading. Plant J. 44, 769-782. doi: 10.1111/j.1365-313X.2005.02569.x

Jin, C. W., You, G. Y., He, Y. F., Tang, C., Wu, P., and Zheng, S. J. (2007). Iron deficiency-induced secretion of phenolics facilitates the reutilization of root apoplastic iron in red clover. Plant Physiol. 144, 278-285. doi: 10.1104/pp.107.095794

Kim, S. A., Punshon, T., Lanzirotti, A., Li, L., Alonso, J. M., Ecker, J. R., et al. (2006). Localization of iron in Arabidopsis seed requires the vacuolar membrane transporter VIT1. Science 314, 1295-1298. doi: 10.1126/science.1132563

Klatte, M., Schuler, M., Wirtz, M., Fink-Straube, C., Hell, R., and Bauer, P. (2009). The analysis of Arabidopsis nicotianamine synthase mutants reveals functions for nicotianamine in seed iron loading and iron deficiency responses. Plant Physiol. 150, 257-271. doi: 10.1104/pp.109.136374

Kneen, B. E., Larue, T. A., Welch, R. M., and Weeden, N. F. (1990). Pleiotropic effects of brz: a mutation in Pisum sativum (L.) cv sparkle conditioning decreased nodulation and increased iron uptake and leaf necrosis. Plant Physiol. 93, 717-722. doi: 10.1104/pp.93.2.717

Kobayashi, T., Itai, R. N., Aung, M. S., Senoura, T., Nakanishi, H., and Nishizawa, N. K. (2012). The rice transcription factor IDEF1 directly binds to iron and other divalent metals for sensing cellular iron status. Plant J. 69, 81-91. doi: 10.1111/j.1365-313X.2011.04772.x

Kobayashi, T., Nagasaka, S., Senoura, T., Itai, R. N., Nakanishi, H., and Nishizawa, N. K. (2013). Iron-binding haemerythrin RING ubiquitin ligases regulate plant iron responses and accumulation. Nat. Commun. 4, 2792. doi: $10.1038 /$ ncomms 3792

Kobayashi, T., and Nishizawa, N. K. (2012). Iron uptake, translocation, and regulation in higher plants. Annu. Rev. Plant Biol. 63, 131-152. doi: 10.1146/annurev-arplant-042811-105522

Kobayashi, T., and Nishizawa, N. K. (2014). Iron sensors and signals in response to iron deficiency. Plant Sci. 224, 36-43. doi: 10.1016/j.plantsci.2014.04.002

Kobayashi, T., and Nishizawa, N. K. (2015). Intracellular iron sensing by the direct binding of iron to regulators. Front. Plant Sci. 6:155. doi: 10.3389/fpls.2015.00155

Kobayashi, T., Yoshihara, T., Jiang, T., Goto, F., Nakanishi, H., Mori, S., et al. (2003). Combined deficiency of iron and other divalent cations mitigates the symptoms of iron deficiency in tobacco plants. Physiol. Plant. 119, 400-408. doi: 10.1034/j.1399-3054.2003.00126.x

Krüger, C., Berkowitz, O., Stephan, U. W., and Hell, R. (2002). A metal-binding member of the late embryogenesis abundant protein family transports iron in the phloem of Ricinus communis L. J. Biol. Chem. 277, 25062-25069. doi: 10.1074/jbc.M201896200

Kruszewski, M. (2004). The role of labile iron pool in cardiovascular diseases. Acta Biochim. Pol. 51, 471-480.

Kuchar, J., and Hausinger, R. P. (2004). Biosynthesis of metal sites. Chem. Rev. 104, 509-526. doi: 10.1021/cr020613p

Kumar, C., Igbaria, A., D'autreaux, B., Planson, A. G., Junot, C., Godat, E., et al. (2011). Glutathione revisited: a vital function in iron metabolism and ancillary role in thiol-redox control. EMBO J. 30, 2044-2056. doi: 10.1038/emboj.2011.105

Lan, P., Li, W., Wen, T.-N., Shiau, J.-Y., Wu, Y.-C., Lin, W., et al. (2011). iTRAQ protein profile analysis of Arabidopsis roots reveals new aspects critical for iron homeostasis. Plant Physiol. 155, 821-834. doi: 10.1104/pp.110.169508

Lanquar, V., Grossmann, G., Vinkenborg, J. L., Merkx, M., Thomine, S., and Frommer, W. B. (2014). Dynamic imaging of cytosolic zinc in Arabidopsis roots combining FRET sensors and RootChip technology. New Phytol. 202, 198-208. doi: $10.1111 / \mathrm{nph} .12652$

Lanquar, V., Lelièvre, F., Bolte, S., Hamès, C., Alcon, C., Neumann, D., et al. (2005). Mobilization of vacuolar iron by AtNRAMP3 and AtNRAMP4 is essential for seed germination on low iron. EMBO J. 24, 4041-4051. doi: 10.1038/sj.emboj.7600864

Larbi, A., Morales, F., Abadia, A., and Abadia, J. (2010). Changes in iron and organic acid concentrations in xylem sap and apoplastic fluid of iron-deficient Beta vulgaris plants in response to iron resupply. J. Plant Physiol. 167, 255-260. doi: 10.1016/j.jplph.2009.09.007

Lattanzio, G., Andaluz, S., Matros, A., Calvete, J. J., Kehr, J., Abadía, A., et al. (2013). Protein profile of Lupinus texensis phloem sap exudates: 
searching for $\mathrm{Fe}$ - and $\mathrm{Zn}$-containing proteins. Proteomics 13, 2283-2296. doi: 10.1002/pmic. 201200515

Ling, H.-Q., Koch, G., Bäumlein, H., and Ganal, M. W. (1999). Map-based cloning of chloronerva, a gene involved in iron uptake of higher plants encoding nicotianamine synthase. Proc. Natl. Acad. Sci. U.S.A. 96, 7098-7103. doi: 10.1073/pnas.96.12.7098

Long, T. A., Tsukagoshi, H., Busch, W., Lahner, B., Salt, D. E., and Benfey, P. N. (2010). The bHLH transcription factor POPEYE regulates response to iron deficiency in Arabidopsis roots. Plant Cell 22, 2219-2236. doi: 10.1105/tpc.110.074096

Lubkowitz, M. (2011). The oligopeptide transporters: a small gene family with a diverse group of substrates and functions? Mol. Plant 4, 407-415. doi: $10.1093 / \mathrm{mp} / \mathrm{ssr} 004$

Maas, F. M., Van De Wetering, D. A., Van Beusichem, M. L., and Bienfait, H. F. (1988). Characterization of phloem iron and its possible role in the regulation of Fe-efficiency reactions. Plant Physiol. 87, 167-171. doi: 10.1104/pp.87.1.167

Marschner, H. (1995). Mineral Nutrition of Higher Plants. San Diego: Academic Press.

Marschner, H., and Romheld, V. (1994). Strategies of plants for acquisition of iron. Plant Soil 165, 261-274. doi: 10.1007/Bf00008069

Martell, A. E., and Smith, R. M. (1974). Critical Stability Constants. New York, NY: Springer.

Mendoza-Cozatl, D. G., Xie, Q., Akmakjian, G. Z., Jobe, T. O., Patel, A., Stacey, M. G., et al. (2014). OPT3 is a component of the iron-signaling network between leaves and roots and misregulation of OPT3 leads to an over-accumulation of cadmium in seeds. Mol. Plant. 7, 1455-1469. doi: 10.1093/mp/ssu067

Morrissey, J., Baxter, I. R., Lee, J., Li, L., Lahner, B., Grotz, N., et al. (2009). The ferroportin metal efflux proteins function in iron and cobalt homeostasis in Arabidopsis. Plant Cell 21, 3326-3338. doi: 10.1105/tpc.109.069401

Mühlenhoff, U., Molik, S., Godoy, J. R., Uzarska, M. A., Richter, N., Seubert, A., et al. (2010). Cytosolic monothiol glutaredoxins function in intracellular iron sensing and trafficking via their bound iron-sulfur cluster. Cell Metab. 12, 373-385.

Mukherjee, I., Campbell, N., Ash, J., and Connolly, E. (2006). Expression profiling of the Arabidopsis ferric chelate reductase (FRO) gene family reveals differential regulation by iron and copper. Planta 223, 1178-1190. doi: 10.1007/s00425005-0165-0

Mustroph, A., Zanetti, M. E., Jang, C. H., Holtan, H. E., Repetti, P. P., Galbraith, D. W., et al. (2009). Profiling translatomes of discrete cell populations resolves altered cellular priorities during hypoxia in Arabidopsis. Proc. Natl. Acad. Sci. U.S.A. 106, 18843-18848. doi: 10.1073/pnas.0906131106

Noctor, G., Mhamdi, A., Chaouch, S., Han, Y. I., Neukermans, J., MarquezGarcia, B., et al. (2012). Glutathione in plants: an integrated overview. Plant Cell Environ. 35, 454-484. doi: 10.1111/j.1365-3040.2011.02400.x

Pasternak, M., Lim, B., Wirtz, M., Hell, R., Cobbett, C. S., and Meyer, A. J. (2008). Restricting glutathione biosynthesis to the cytosol is sufficient for normal plant development. Plant J. 53, 999-1012. doi: 10.1111/j.1365-313X.2007.0 3389.x

Pich, A., and Scholz, G. (1996). Translocation of copper and other micronutrients in tomato plants (Lycopersicon esculentum Mill.): nicotianamine-stimulated copper transport in the xylem. J. Exp. Bot. 47, 41-47. doi: 10.1093/jxb/4 7.1 .41

Rellán-Álvarez, R., Abadía, J., and Álvarez-Fernández, A. (2008). Formation of metal-nicotianamine complexes as affected by $\mathrm{pH}$, ligand exchange with citrate and metal exchange. A study by electrospray ionization time-of-flight mass spectrometry. Rapid Commun. Mass Spectrom. 22, 1553-1562. doi: $10.1002 / \mathrm{rcm} .3523$

Rellan-Alvarez, R., Giner-Martinez-Sierra, J., Orduna, J., Orera, I., RodriguezCastrillon, J. A., Garcia-Alonso, J. I., et al. (2010). Identification of a tri-iron(III), tri-citrate complex in the xylem sap of iron-deficient tomato resupplied with iron: new insights into plant iron long-distance transport. Plant Cell Physiol. 51, 91-102. doi: 10.1093/pcp/pcp170

Robinson, N. J., Procter, C. M., Connolly, E. L., and Guerinot, M. L. (1999). A ferric-chelate reductase for iron uptake from soils. Nature 397, 694-697. doi: $10.1038 / 17800$

Rodríguez-Celma, J., Lin, W.-D., Fu, G.-M., Abadía, J., López-Millán, A.F., and Schmidt, W. (2013). Mutually exclusive alterations in secondary metabolism are critical for the uptake of insoluble iron compounds by
Arabidopsis and Medicago truncatula. Plant Physiol. 162, 1473-1485. doi: 10.1104/pp.113.220426

Rodríguez-Celma, J., and Schmidt, W. (2013). Reduction-based iron uptake revisited. Plant Signal. Behav. 8, e26116. doi: 10.4161/psb.26116

Rodríguez-Celma, J., Vázquez-Reina, S., Orduna, J., Abadía, A., Abadía, J., ÁlvarezFernández, A., et al. (2011). Characterization of flavins in roots of fe-deficient strategy i plants, with a focus on Medicago truncatula. Plant Cell Physiol. 52, 2173-2189. doi: 10.1093/pcp/pcr149

Rogers, E. E., and Guerinot, M. L. (2002). FRD3, a member of the multidrug and toxin efflux family, controls iron deficiency responses in Arabidopsis. Plant Cell 14, 1787-1799. doi: 10.1105/tpc.001495

Romera, F. J., Alcántara, E., and De La Guardia, M. D. (1992). Role of roots and shoots in the regulation of the Fe efficiency responses in sunflower and cucumber. Physiol. Plant. 85, 141-146. doi: 10.1111/j.1399-3054.1992.tb0 4716.x

Roschzttardtz, H., Conejero, G., Curie, C., and Mari, S. (2009). Identification of the endodermal vacuole as the iron storage compartment in the Arabidopsis embryo. Plant Physiol. 151, 1329-1338. doi: 10.1104/pp.109.144444

Roschzttardtz, H., Séguéla-Arnaud, M., Briat, J.-F., Vert, G., and Curie, C. (2011). The FRD3 citrate effluxer promotes iron nutrition between symplastically disconnected tissues throughout Arabidopsis development. Plant Cell 23, 27252737. doi: 10.1105/tpc.111.088088

Santi, S., and Schmidt, W. (2009). Dissecting iron deficiency-induced proton extrusion in Arabidopsis roots. New Phytol. 183, 1072-1084. doi: 10.1111/j.1469-8137.2009.02908.x

Schaaf, G., Schikora, A., Haberle, J., Vert, G., Ludewig, U., Briat, J. F., et al. (2005). A putative function for the Arabidopsis Fe-Phytosiderophore transporter homolog AtYSL2 in Fe and Zn homeostasis. Plant Cell Physiol. 46, 762-774.

Schmid, N. B., Giehl, R. F. H., Döll, S., Mock, H.-P., Strehmel, N., Scheel, D., et al. (2014). Feruloyl-CoA 6' -hydroxylase1-dependent coumarins mediate iron acquisition from alkaline Substrates in Arabidopsis. Plant Physiol. 164, 160-172. doi: 10.1104/pp.113.228544

Schmidt, W., Boomgaarden, B., and Ahrens, V. (1996). Reduction of root iron in Plantago lanceolata during recovery from Fe deficiency. Physiol. Plant. 98, 587-593. doi: 10.1111/j.1399-3054.1996.tb05715.x

Schnaubelt, D., Queval, G., Dong, Y., Diaz-Vivancos, P., Makgopa, M. E., Howell, G., et al. (2015). Low glutathione regulates gene expression and the redox potentials of the nucleus and cytosol in Arabidopsis thaliana. Plant Cell Environ. 38, 266-279. doi: 10.1111/pce.12252

Scholz, G., Schlesier, G., and Seifert, K. (1985). Effect of nicotianamine on iron uptake by the tomato mutant 'chloronerva'. Physiol. Plant. 63, 99-104. doi: 10.1111/j.1399-3054.1985.tb02825.x

Schuler, M., Rellán-Álvarez, R., Fink-Straube, C., Abadía, J., and Bauer, P. (2012). Nicotianamine functions in the phloem-based transport of iron to sink organs, in pollen development and pollen tube growth in Arabidopsis. Plant Cell 24, 2380-2400. doi: 10.1105/tpc.112.099077

Selote, D., Samira, R., Matthiadis, A., Gillikin, J. W., and Long, T. A. (2015). Iron-binding e3 ligase mediates iron response in plants by targeting basic helix-loop-helix transcription factors. Plant Physiol. 167, 273-286. doi: 10.1104/pp.114.250837

Shanmugam, V., Tsednee, M., and Yeh, K.-C. (2012). ZINC TOLERANCE INDUCED BY IRON 1 reveals the importance of glutathione in the crosshomeostasis between zinc and iron in Arabidopsis thaliana. Plant J. 69, 10061017. doi: 10.1111/j.1365-313X.2011.04850.x

Silva, J. J. R. F. D., and Williams, R. J. P. (2001). The Biological Chemistry of the Elements: The Inorganic Chemistry of Life. Oxford: Oxford University Press.

Sipos, K., Lange, H., Fekete, Z., Ullmann, P., Lill, R., and Kispal, G. (2002). Maturation of cytosolic iron-sulfur proteins requires glutathione. J. Biol. Chem. 277, 26944-26949. doi: 10.1074/jbc.M200677200

Stacey, M. G., Koh, S., Becker, J., and Stacey, G. (2002). AtOPT3, a member of the oligopeptide transporter family, is essential for embryo development in Arabidopsis. Plant Cell 14, 2799-2811. doi: 10.1105/tpc.005629

Stacey, M. G., Patel, A., Mcclain, W. E., Mathieu, M., Remley, M., Rogers, E. E., et al. (2008). The Arabidopsis AtOPT3 protein functions in metal homeostasis and movement of iron to developing seeds. Plant Physiol. 146, 589-601. doi: 10.1104/pp.107.108183

Thomine, S., Lelièvre, F., Debarbieux, E., Schroeder, J. I., and Barbier-Brygoo, H. (2003). AtNRAMP3, a multispecific vacuolar metal transporter involved in 
plant responses to iron deficiency. Plant J. 34, 685-695. doi: 10.1046/j.1365313X.2003.01760.x

Valko, M., Morris, H., and Cronin, M. T. (2005). Metals, toxicity and oxidative stress. Curr. Med. Chem. 12, 1161-1208. doi: 10.2174/0929867053764635

Vert, G. A., Briat, J.-F., and Curie, C. (2003). Dual regulation of the arabidopsis high-affinity root iron uptake system by local and long-distance signals. Plant Physiol. 132, 796-804. doi: 10.1104/pp.102.016089

Vert, G., Grotz, N., Dédaldéchamp, F., Gaymard, F., Guerinot, M. L., Briat, J.-F., et al. (2002). IRT1, an Arabidopsis transporter essential for iron uptake from the soil and for plant growth. Plant Cell 14, 1223-1233. doi: 10.1105/tpc.001388

Vigani, G., Morandini, P., and Murgia, I. (2013a). Searching iron sensors in plants by exploring the link among 2'-OG-dependent dioxygenases, the iron deficiency response and metabolic adjustments occurring under iron deficiency. Front. Plant Sci. 31:169. doi: 10.3389/fpls.2013.00169

Vigani, G., Zocchi, G., Bashir, K., Philippar, K., and Briat, J. F. (2013b). Signals from chloroplasts and mitochondria for iron homeostasis regulation. Trends Plant Sci. 18, 305-311. doi: 10.1016/j.tplants.2013.01.006

von Wiren, N., Klair, S., Bansal, S., Briat, J. F., Khodr, H., Shioiri, T., et al. (1999). Nicotianamine chelates both FeIII and FeII. Implications for metal transport in plants. Plant Physiol. 119, 1107-1114.

Wachter, A., Wolf, S., Steininger, H., Bogs, J., and Rausch, T. (2005). Differential targeting of GSH1 and GSH2 is achieved by multiple transcription initiation: implications for the compartmentation of glutathione biosynthesis in the Brassicaceae. Plant J. 41, 15-30. doi: 10.1111/j.1365-313X.2004.02269.x

Waldron, K. J., Rutherford, J. C., Ford, D., and Robinson, N. J. (2009). Metalloproteins and metal sensing. Nature 460, 823-830. doi: 10.1038 /nature 08300

Walker, E. L., and Connolly, E. L. (2008). Time to pump iron: iron-deficiencysignaling mechanisms of higher plants. Curr. Opin. Plant Biol. 11, 530-535.

Wang, B., Li, Y., and Zhang, W.-H. (2012). Brassinosteroids are involved in response of cucumber (Cucumis sativus) to iron deficiency. Ann. Bot. 110, 681-688. doi: 10.1093/aob/mcs126

Waters, B. M., and Armbrust, L. C. (2013). Optimal copper supply is required for normal plant iron deficiency responses. Plant Signal. Behav. 8, e26611. doi: $10.4161 /$ psb. 26611
Waters, B. M., Blevins, D. G., and Eide, D. J. (2002). Characterization of FRO1, a pea ferric-chelate reductase involved in root iron acquisition. Plant Physiol. 129, 85-94. doi: 10.1104/pp.010829

Waters, B. M., Chu, H.-H., Didonato, R. J., Roberts, L. A., Eisley, R. B., Lahner, B., et al. (2006). Mutations in Arabidopsis yellow stripe-like1 and yellow stripe-like3 reveal their roles in metal ion homeostasis and loading of metal ions in seeds. Plant Physiol. 141, 1446-1458. doi: 10.1104/pp.106. 082586

Waters, B. M., Mcinturf, S. A., and Stein, R. J. (2012). Rosette iron deficiency transcript and microRNA profiling reveals links between copper and iron homeostasis in Arabidopsis thaliana. J. Exp. Bot. 63, 5903-5918. doi: $10.1093 /$ jxb/ers239

Williams, R. J. P. (1982). Free manganese(II) and iron(II) cations can act as intracellular cell controls. FEBS Lett. 140, 3-10.

Wintz, H., Fox, T., Wu, Y. Y., Feng, V., Chen, W. Q., Chang, H. S., et al. (2003). Expression profiles of Arabidopsis thaliana in mineral deficiencies reveal novel transporters involved in metal homeostasis. J. Biol. Chem. 278, 47644-47653. doi: 10.1074/jbc.M309338200

Zhai, Z. (2011). Identification of Heavy Metal Transporters. Doctor of Philosophy Dissertation. Ithaca, NY: Cornell University.

Zhai, Z., Gayomba, S. R., Jung, H. I., Vimalakumari, N. K., Pineros, M., Craft, E., et al. (2014). OPT3 is a phloem-specific iron transporter that is essential for systemic iron signaling and redistribution of iron and cadmium in Arabidopsis. Plant Cell 26, 2249-2264. doi: 10.1105/tpc.114.123737

Conflict of Interest Statement: The authors declare that the research was conducted in the absence of any commercial or financial relationships that could be construed as a potential conflict of interest.

Copyright (c) 2015 Gayomba, Zhai, Jung and Vatamaniuk. This is an open-access article distributed under the terms of the Creative Commons Attribution License (CC BY). The use, distribution or reproduction in other forums is permitted, provided the original author(s) or licensor are credited and that the original publication in this journal is cited, in accordance with accepted academic practice. No use, distribution or reproduction is permitted which does not comply with these terms. 